and micrococci, it is upon the destruction of these with their extraordinary power of development and multiplication that our success depends. For this purpose I use the following mixture as a spray: Oil of eucalyptus, two drachms ; terebene, two drachms ; rectified spirit of wine, one ounce and a half. When used, the spray machine is held at a short distance from the mouth, which is opened to receive the spray. I generally order it to be used half an hour before each meal and at bedtime, thus ensuring a constantly ozonised breathing atmosphere. Internally I give terebene in drop doses to a child of from one to three years of age in combination with two grains of carbonate of magnesia and ten minims of compound tincture of camphor to one or two teaspoonfuls of water, repeated every three hours. The two former constituents to be triturated together, the magnesia being used simply as a carriage for the terebene, which is not miscible with water. The paregoric allays the irritability of the cough until the disease succumbs to the specific treatment. The machine I usually recommend for spraying is an ordinary odorator. A cheap form is one represented in Fig. 183, Sec. VI., in Maw's Catalogue, and can be used either with or without bellows. In every case where the above treatment has been properly carried out I have effected cures in about a fortnight. About a week after the characteristic "hoop" has become developed the paroxysms gradually become reduced in frequency and violence, until they cease to be noticed at all.

Dovercourt.

\section{DISLOCATION ON TO THE DORSUM ILII IN A} CHILD SIX YEARS OLD.

By C. Lyne Dixson, M.B., M.R.C.S.

IN reading the case recorded in THE LANCET of Oct. 12th of dislocation on to the dorsum ilii in a child seven years old, which occurred at the Taunton and Somerset Hospital, under the care of Mr. Farrant, I was reminded of a similar case which came under my notice two years ago.

Riding one evening through a village on the North Tyne, I was suddenly called into a cottage to see a little girl, six years old, who had fallen out of the back of a cart, with her leg bent under her as she fell-at least, so the story was told. On examination, I found a distinct dislocation of the head of the right femur on to the dorsum ilii. She seemed in great pain and distress, and would not let me handle the limb at all. As in the case recorded, the thigh was semiflexed, adducted, and rotated inwards, the great toe resting on the dorsum of the left foot. As the pain seemed excessive and the child was very nervous and frightened, I returned for some chloroform; then, by the light of a candle and with the aid of the mother, I placed the child on the floor on her back, with only a pillow under her head. Having administered the ancesthetic, I removed my left boot, and placing my foot on the right ilium, I made extension of the right leg by pulling the limb at right angles to the body. Immediately the bone returned to its place with an audible click. An outside splint and a fortnight in bed, and the child was sufficiently well to get about; at the end of a month she was as well as ever.

I have recorded this interesting and rare case owing to its very close resemblance to the one I have already referred to, the only difference being that the patient was of the other sex and a year younger, and the right limb, instead of the left, was the one affected. The treatment I adopted was not the same, but the result was equally good.

Llantwit Major, S. Wales.

\section{EXPERIMENTS ON THE ACTION OF SYZYGIUM JAMBOLANUM IN ARTIFICIAL DIABETES.}

By Dr. C. Graeser.

I HAVE recently had the opportunity, through the kindness of Professor Binz, of making, in the Pharmacological Institute at Bonn, some experiments with extracts of the fruit of syzygium jambolanum upon dogs rendered diabetic by phloridzin. The plant is a tree of the group Eugenioideæ, subfamily Myrtex, indigenous in tropical America, the West and East Indies, where its acid fruit is eaten. When at Java I learnt that the plant is called "djamelang" by the natives, who use the fruit and bast for diarrhoea and diabetes. Since its introduction into Europe as jambul it has also been here employed in diabetes. ${ }^{1}$ In order to test its action more carefully, and to see whether and to what extent it may influence artificial diabetes, or what toxic effects it may possess, I made some dogs diabetic by phloridzin, following the instructions of von Mehrung. By administering from 2.5 to 4.8 grm. of phloridzin daily to young dogs (weighing 2700 to $4800 \mathrm{grm}$.) in the proportion of 1 grm. per kilo of body-weight, there ensues an excretion of sugar lasting for twenty-four to thirty-six hours, and amounting to from 5.89 to $12.45 \mathrm{grms}$. At first I gave the phloridzin in one dose, later in gramme doses. every two or three hours, without any notable difference in the amount of sugar excreted. In three experiments some diarrhœa was set up. In each case, whenever either before, with, or after the phloridzin, the animal was given extract of syzygium jambolanum, the sugar excretion invariably fell, in some cases to about nine-tenths of the amount excreted under phloridzin alone, in all it was diminished to at least one-half. At the same time the period of excretion was curtailed. Thus whilst with phloridzin alone the amount of sugar was from 5.89 to $12.45 \mathrm{grm}$., the amount (with the same dose of phloridzin) under treatment by jambul was maximum 2906 , minimum $1.5 \mathrm{grm}$. With a drug of which the action begins and ceases within a limited time, its antidote must also act in a definite time and in corresponding quantity, to be determined by experiment. So that if such a diminution in the excretion of sugar takes place as related in these experiments-viz., nine-tenths-by the use of jambul, its more accurate employment might perhaps completely check this excretion. The cunditions in diabetes mellitus are far better suited to test this, besides showing the agreement between phloridzin diabetes and the natural disease. This research is of special value as showing that the syzygium jambolanum may be used in diabetes mellitus in the human subject much more freely and in larger doses than hitherto for in no direction were any effects observed whith would contraindicate its use. There was no sign of any toxic action even in the dog which had a daily dose of jambul extract. In one experiment there occurred some diarrhoea, but this happened in later experiments with phloridzin alone, and was probably attributable to the latter. In all the experiments extracts of the syzygium jambul were used which had been prepared by R. H. Davies, F.I.C., of the Society of Apothecaries, London, from fruits I had brought over with me. The extracts were partly made from the whole fruit, partly from the rind or kernel, and concentrated so that $100 \mathrm{grm}$. of fruit were represented by $16 \frac{1}{3} \mathrm{grm}$. of the kernel and 11 告 grm. of the rind extract. The dose was 6 to $18 \mathrm{grm}$. daily. It is still uncertain whether the active principle is in the rind or the kernel-probably in both, but more in the former.

The results of three sets of observations may be thus summarised:-

\begin{tabular}{|c|c|c|c|}
\hline & $\begin{array}{c}\text { Grms. } \\
12.5\end{array}$ & \begin{tabular}{cc}
\multicolumn{2}{c}{ Grms. } \\
$\ldots$. & $10^{\circ} 0$
\end{tabular} & $\begin{array}{r}\text { Grms } \\
. \quad 105\end{array}$ \\
\hline $\begin{array}{l}\text { ed with phloridzin } \\
\ldots \\
1 .\end{array}$ & $2 \cdot 1$ & 1.0 & \\
\hline duction in sugar .. & $80 \cdot 8$ & $84: 0$ & \\
\hline
\end{tabular}
Bonn.

\section{POISONING BY PHOSPHORUS.}

By Samuer Grose, M.D. ST. AND., F.R.C.S. ENG.

A GIRL, aged three years and a half, ate some phosphorus paste. There was slight sickness at first, little or no pain, no fever, and yet constant thirst ; apathy, gradually deepening into convulsions and coma; jaundice with white stools: dribbling of coffee-grounds-like fluid from the mouth; and death on the fifth day.

After death the liver was found much enlarged and in a state of acute fatty degeneration. Heart and kidneys felt greasy on section. On the third and fourth day, the urine gave no deposit on boiling or on addition of nitric acid, but it reduced the copper in Felling's solution. May the presence of sugar in urine help to distinguish between those poisoned by phosphorus and sufferers from acute yellow hepatic degeneration, the symptoms in both being very similar?

1 See Bernhard Schuchardt, Centralbl. fur Klin. Med., 1889, No. 28. \& Verhandl, der Kongr. für Innere Med., Wiesbaden, 1886 